\title{
Cardiac involvement in Churg-Strauss syndrome shown by echocardiography
}

\author{
J M MORGAN, L RAPOSO, D G GIBSON \\ From the Cardiac Department, Brompton Hospital, London
}

SUMMARY To define the range of cardiac involvement in the Churg-Strauss syndrome, $M$ mode, continuous wave Doppler, and cross sectional echocardiograms were recorded in twelve patients with the disorder. The $M$ mode recordings were digitised and the cross sectional images were recorded with standardised gain settings to determine regional myocardial echo amplitude. Left ventricular end diastolic and end systolic dimensions were increased above the normal $95 \%$ confidence interval in four patients, three of whom showed a depressed shortening fraction. Mitral regurgitation was present in six patients; this was severe enough to need valve replacement in two. Mean echo amplitude in both the septum and the posterior wall was significantly increased above normal by a mean (SD) of $4.87(2.57) \mathrm{dB}$, suggesting the presence of myocardial fibrosis. There was no evidence of subendocardial involvement as there is in other hypereosinophilic syndromes.

Mitral regurgitation is common in the Churg-Strauss syndrome. This cannot be ascribed to involvement of the cusps or chordae and it occurs even when ventricular function is well preserved. It is suggested that mitral regurgitation is caused by diffuse myocardial fibrosis.

The Churg-Strauss syndrome is recognised by the combination of blood eosinophilia, eosinophilic tissue infiltration, extravascular fibrinoid necrotising (allergic) epithelioid and eosinophilic granuloma formation, and disseminated necrotising vasculitis occurring in asthmatic patients. ${ }^{12}$ Lanham et al noted that "the histological components of the syndrome often do not coexist temporally or spatially" and suggested that the clinical pattern of a prodromal phase of allergic disease, followed by a second phase characterised by eosinophilic tissue infiltration and peripheral blood eosinophilia culminating in a third vasculitic phase, should supercede strict adherence to histopathological criteria for the purposes of diagnosis. ${ }^{3}$ Myocardial fibrosis, particularly in the subendocardial region, is a characteristic feature of the idiopathic hypereosinophilic syndrome ${ }^{4}$ and it has been attributed directly to the eosinophilia itself. Possible cardiac involvement in patients with ChurgStrauss syndrome and comparable blood eosinophilia, however, is less well defined. We therefore studied a series of patients with Churg-Strauss syndrome by $\mathbf{M}$ mode, continuous wave Doppler, and cross sectional echocardiography to assess whether they were also at risk for heart disease.

Requests for reprints to Dr J M Morgan, National Heart Hospital, London W1M 8BA.

Accepted for publication 6 April 1989

\section{Patients and methods}

We studied 12 patients in whom the diagnosis of Churg-Strauss syndrome was made on the basis of histological criteria ${ }^{12}$ and clinical features. ${ }^{3}$ The blood eosinophil count was raised in all (eosinophil counts ranged from 2.3 to $11 \times 10^{9} 1$ at presentation). The results of echocardiography were compared with those in 20 age and sex matched controls with no clinical evidence of heart disease in whom stress test had been negative at high workload.

\section{ECHOCARDIOGRAPHY}

Cross sectional echocardiograms were recorded in parasternal views. The regional echo amplitude was displayed in real time by a Brompton encoder. ${ }^{5}$ The master gain setting of the echocardiograph was standardised as the lowest level at which the parietal pericardium behind the posterior left ventricular wall appeared as a continuous line at the highest level of pixel intensity (white on the display), and the depth compensation was adjusted to give linear change across the image. Echocardiographic images were recorded on $3 / 4$ inch tape by a Sony U-matic recorder for further study.

End diastolic stop frame images were subsequently displayed by a tape recorder with digital frame advance (Sony 5800 PS). Four areas of interest were identified: mid and basal septum and mid and basal 
posterior wall. We took care to limit sampling to these areas on the myocardium itself and to avoid specular echoes from the endocardium or epicardium. In each region approximately 300 pixels were included within the area of interest. From each the distribution of pixel intensity in each of the 64 grey scale levels was displayed as a histogram, and printed separately. Mean and median pixel levels for each region were calculated.

$M$ mode echocardiograms were recorded under cross sectional control from the level of the tips of the mitral leaflets at a paper speed of $100 \mathrm{~m} / \mathrm{s}$ with a simultaneous phonocardiogram and electrocardiogram. They showed clear, continuous echoes from the left side of the septum and the endocardial surface of the posterior wall.

$M$ mode echocardiograms were digitised, ${ }^{6}$ and the following measurements were made: $(a)$ maximum and minimum cavity diameter; (b) fractional shortening; (c) septal and posterior wall thickness; (d) percentage increase in posterior wall thickness during systole; (e) peak rate of change of cavity dimension during systole and diastole; and $(f)$ peak rate of change of posterior wall thickness during systole and diastole.

Continuous wave Doppler cardiograms were recorded from the apex with a Doptek Spectrascan along with a simultaneous phonocardiogram and electrocardiogram. The aim was to detect the presence or absence or the typical flow-velocity signal of mitral regurgitation. If it was present, we

Table 1 Left ventricular cavity size and fractional shortening in patients with mitral regurgitation

\begin{tabular}{lllll}
\hline Patient & $L V-E D-\operatorname{dim}$ & $L V-E S-\operatorname{dim}$ & $\%$ FS & Duration $M R(\mathrm{~ms})$ \\
\hline 1 & $6 \cdot 3$ & $5 \cdot 4$ & 15 & 100 \\
$2^{\star}$ & $7 \cdot 4$ & $6 \cdot 1$ & 18 & 40 \\
3 & $6 \cdot 5$ & 6 & $8 \cdot 4$ & 90 \\
$4^{\star}$ & $6 \cdot 2$ & 4 & 35 & N/A \\
5 & $5 \cdot 3$ & 3 & 44 & N/A \\
6 & 5 & $3 \cdot 1$ & 44 & 90 \\
& $3 \cdot 5-5 \cdot 5$ & $2 \cdot 1-3 \cdot 7$ & $25-47$ & \\
& $(95 \%$ confidence interval) & &
\end{tabular}

^Later underwent mitral valve replacement. N/A, not available; LV-ED-dim, left ventricular end diastolic cavity dimension $(\mathrm{cm})$; LV-ES-dim, left ventricular end systolic dimension $(\mathrm{cm}) ; \%$ FS, percentage fractional shortening; MR, mitral regurgitation after aortic valve closure. noted the time that it stopped in relation to the onset of the aortic component of the second heart sound (fig 1$)^{7}$

\section{STATISTICAL ANALYSIS}

We compared results of $M$ mode digitisation and myocardial echo amplitude estimates in the patients with Churg-Strauss syndrome with $95 \%$ confidence intervals for normal controls. Student's $t$ test was used to determine statistical significance.

\section{Results}

\section{CONTINUOUS WAVE DOPPLER}

Mitral regurgitation was recorded by continuous wave Doppler in six of twelve patients. In four it was judged to be mild on clinical and haemodynamic grounds, and in three of these the regurgitation persisted for more than $50 \mathrm{~ms}$ after the aortic component of the second heart sound. In the fourth the measurement could not be made because $A_{2}$ was not adequately defined on the phonocardiogram. In one of the two remaining patients with mitral regurgitation severe enough to require valve replacement the corresponding interval was $40 \mathrm{~ms}$ while in the other $A_{2}$ was again undefined (table 1).

Overall, there was no significant difference between the patients and controls subjects in any of the measurements made from the digitised $M$ modes. However, the left ventricular cavity dimension and fractional shortening were outside the $95 \%$ confidence intervals for normal in four of the six patients with mitral regurgitation (table 1). In two of the four in whom regurgitation was mild, fractional shortening was also reduced. In the other two patients, however, cavity dimensions and fractional shortening were normal. Cavity dimensions were increased in both the patients with severe regurgitation, fractional shortening being reduced in one and normal in the other. Thus in three of the six patients with mitral regurgitation, fractional shortening was well preserved.

\section{MYOCARDIAL ECHO AMPLITUDE}

Mean myocardial echo amplitude in all twelve patients studied was outside the $95 \%$ confidence intervals for the controls in each of the four regions of myocardium (table 2). Overall, echo amplitude in

Table 2 Myocardial echo amplitude in patients with Churg-Strauss syndrome and controls

\begin{tabular}{lcccc}
\hline Group & $M P W(S D)$ & $B P W(S D)(d B)$ & $M S(S D)(d B)$ & $B S(S D)$ \\
\hline Churg-Strauss & $\star 10.5(3.09)$ & $\star 8.02(2.47)$ & $\star 9.03(3.09)$ & $\star 6.94(2.99)$ \\
Controls & $3.51(0.32)$ & $3.42(0.36)$ & $4.59(0.36)$ & $3.5(0.32)$ \\
\hline
\end{tabular}

$\star_{p}<0.001$, compared with controls; measurements in decibels. MPW, mid posterior wall; BPW, basal posterior wall; MS, mid septum; BS, basal septum. 


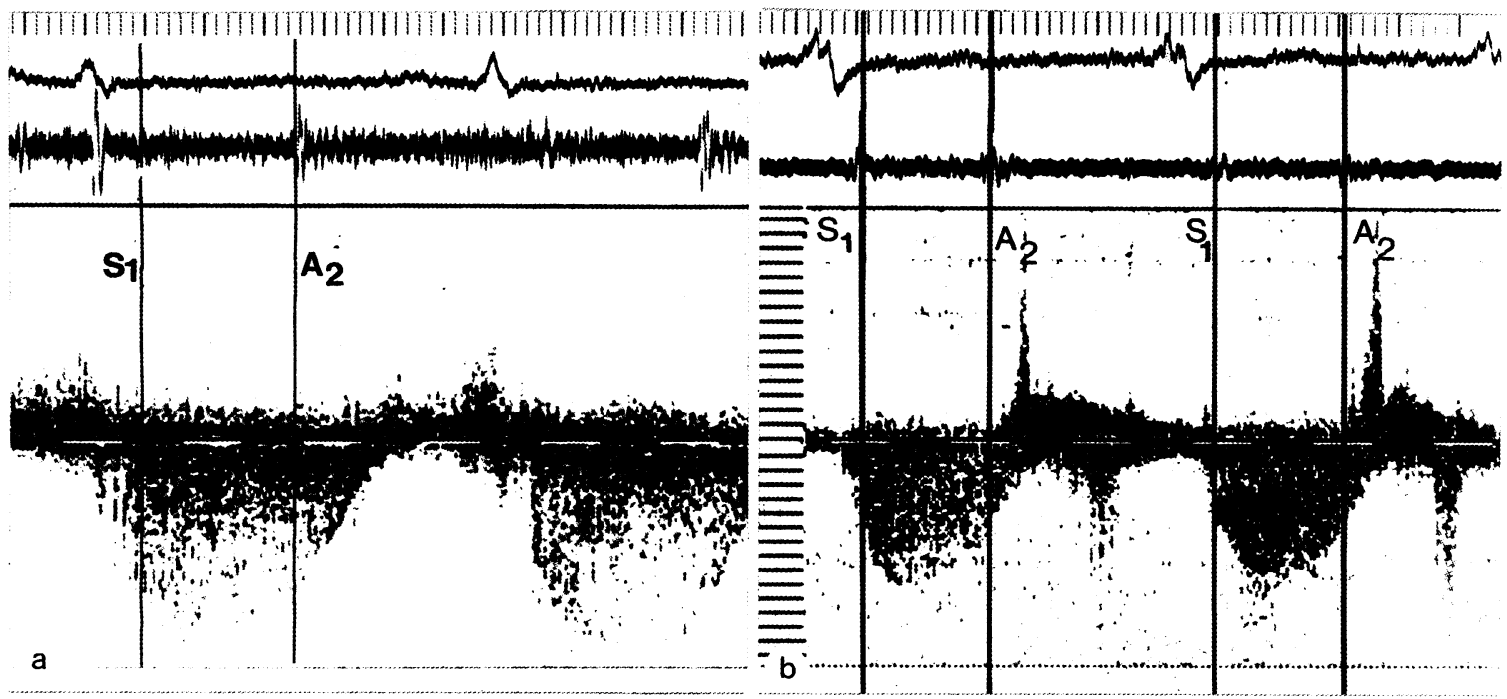

Fig 1 Velocity profile from continuous wave Doppler traces showing (a) mild mitral regurgitation and (b) severe mitral regurgitation and their relation of the end of mitral regurgitation to the aortic component of the second heart sound on the phonocardiogram (paper speed $100 \mathrm{~mm} / \mathrm{s} ; 16 \mathrm{kHz}$ scale). $A_{2}$, aortic component of second heart sound.

patients with the Churg-Strauss syndrome was increased above normal by a mean of $4.87(2.57) \mathrm{dB}$ $(p<0.001)$ in both septum and the posterior wall. Subsequent echocardiography showed that this increase persisted, so that it is unlikely to have been $\mathbb{D}^{\circ}$ caused by myocarditis at the time of diagnosis.

Inspection of the colour encoded images showed no regional increase in echo amplitude (fig 2). In

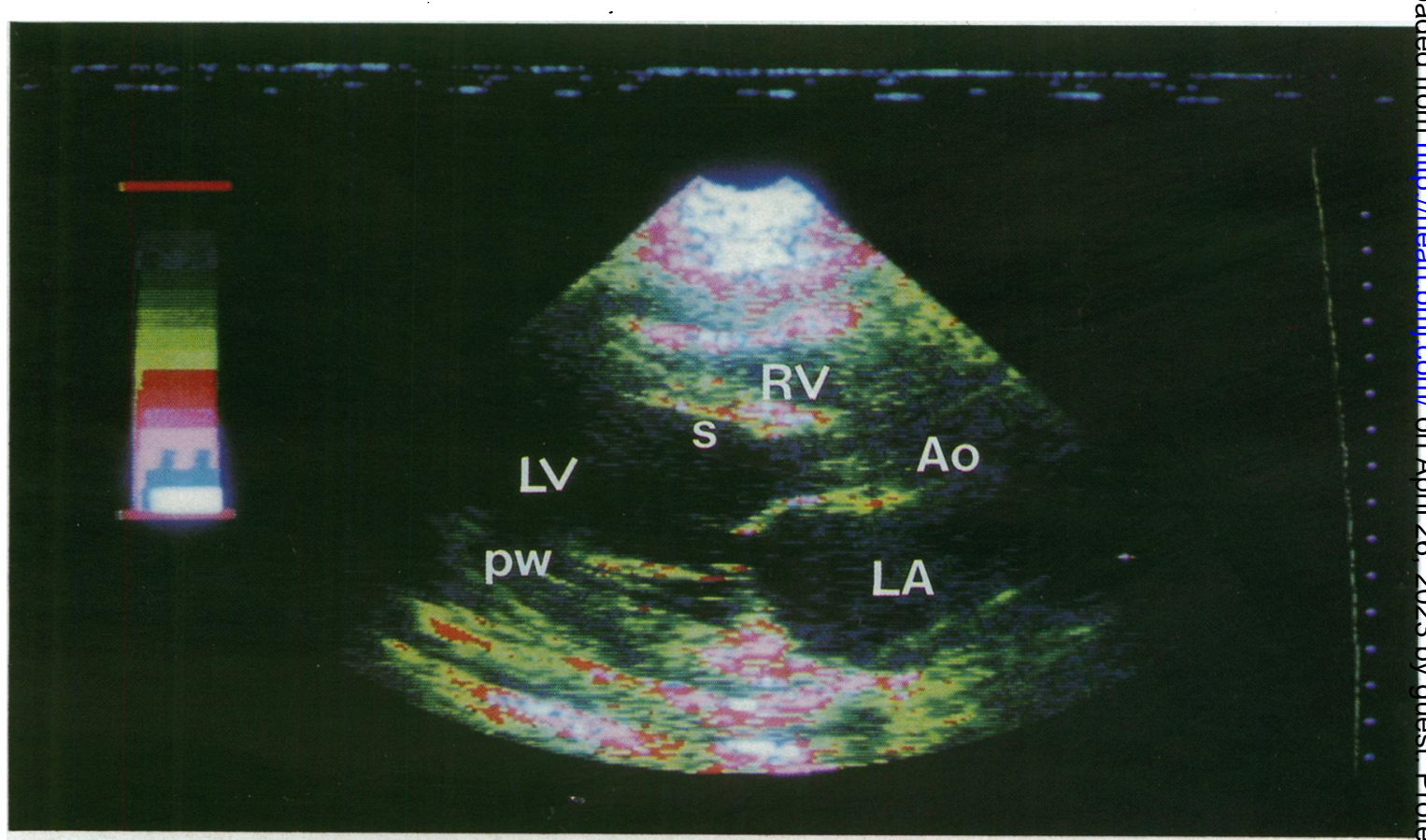

Fig 2 Parasternal long axis view, processed image, showing generalised increase in myocardial echo amplitude. $R V$, right ventricle; $L V$, left ventricle; $L A$, left atrium; Ao, aortic root; $P W$, posterior left ventricular wall; $S$, interventricular septum Highest level of pixel intensity is white (see scale). 
addition, there was no significant difference in amplitude between any of the four sites sampled in the patients, indicating that the distribution of the increase was generalised rather than localised.

\section{Discussion}

The relation between blood eosinophilia and heart disease is well recognised. ${ }^{49}$ Endomyocardial fibrosis is prominent in the hypereosinophilic syndrome and leads to a characteristic clinical picture of restrictive cardiomyopathy accompanied by atrioventricular valve regurgitation when the papillary muscles are affected. ${ }^{40}$ There is much evidence to suggest that these cardiac abnormalities are the direct result of eosinophilia and that they persist even if the eosinophilia itself has subsided. ${ }^{41}$ Thus Chew et al reported eleven cases of subendocardial fibrosis in patients presenting with restrictive cardiomyopathy, although in only two was there documented eosinophilia. ${ }^{12}$

The Churg-Strauss syndrome is distinguished from other causes of hypereosinophilia by specific clinical and histopathological features. Asthma is common but, unlike polyarteritis nodosa, renal involvement is unusual. ${ }^{23}$ Histologically a disseminated necrotising vasculitis affects the small arteries and veins, together with necrotising (allergic) epithelioid and eosinophilia granulomas. Despite the frequent occurrence of eosinophilia, the possibility that clinically significant heart disease might occur in the Churg-Strauss syndrome has received little attention in published reports, even in the original description of cardiac involvement ${ }^{1}$ and was not considered in the large series reported by Chumbley et $a l,{ }^{2}$ despite the frequency of heart disease at necropsy.

More recently, Spry et al noted the presence of diffuse myocardial fibrosis in Churg-Strauss syndrome $^{13}$ and extensive replacement of the myocardium by granulomas and scar tissue has been reported. ${ }^{14}$ Furthermore, Lanham et al noted that cardiac involvement accounted for death in $48 \%$ of patients with the condition. ${ }^{3}$ Davison et al also drew attention to cardiac disease in three patients (included in our series), two of whom had evidence of pericardial involvement and one with additional myocardial disease. ${ }^{15}$ It was for this reason that the present, more comprehensive investigation was undertaken, by non-invasive methods that have proved effective in detecting cardiac involvement in other forms of heart disease associated with hypereosinophilia. Regional echo amplitude has previously been shown to correlate with myocardial collagen content in chronic heart disease. ${ }^{16}$ The method has been used to show localised fibrosis in patients with tropical endomyocardial disease and in endomyocardial fibrosis, ${ }^{17} 18$ especially when it affects the subendocardium and papillary muscles. We found an increase in myocardial echo amplitude in all the patients we studied. But this differed from what we saw in other patients with hypereosinophilia in having a generalised distribution. Theoretically, it might have been caused by myocardial oedema, which we have previously shown to be a cause of increased myocardial echo intensity when it is associated with acute rejection in the transplanted heart. ${ }^{19}$ We think that this is an unlikely cause in the present patients, however, because the increased echo intensities persisted when other acute manifestations of the disease, such as eosinophilia, asthma, and vasculitis, had subsided. We cannot confirm this theory by histology in our patients, because none of them has died and endomyocardial biopsy in one patient yielded an inadequate sample. Nevertheless, we conclude that the increase in myocardial echo intensity reflects the generalised increase in myocardial collagen content as found in previous histological studies.

We were also able to study the effects of this fibrosis on left ventricular function. The results of $\mathrm{M}$ mode digitisation suggested that simple measurements of systolic and diastolic performance were well preserved. Unlike the hypereosinophilic syndrome, ${ }^{8}$ there was no echocardiographic evidence that the valve cusps were affected. Nevertheless, continuous wave Doppler detected the presence of mitral regurgitation in six of the twelve patients, an unexpectedly high frequency. In two of these patients it was severe enough to require mitral valve replacement, and in two of the remaining four, in whom it was mild, left ventricular cavity size was not increased. It was not possible, therefore, to attribute this regurgitation simply to cavity dilatation. We suggest, rather, that it is the direct consequence of fibrosis of the papillary muscles occurring as part of the more generalised myocardial effects seen in this disease.

We conclude, therefore, that myocardial fibrosis of generalised distribution is a notable, though usually subclinical feature of the Churg-Strauss syndrome. It may result in left ventricular disease or, more characteristically, in mitral regurgitation which is more severe, and which may occur at a smaller cavity size than that seen in association with other types of left ventricular disease. We believe that echocardiography should be performed on all cases of the syndrome to document the presence and extent of heart disease, because in some it may play a prominent part in the clinical manifestations of the condition. 
We thank Dr A Newman-Taylor, Professor $M$ Turner-Warwick, Dr D Geddes, and Professor P Barnes for allowing us to investigate their patients.

\section{References}

1 Churg J, Strauss L. Allergic granulomatosis, vasculitic angitiis and periarteritis nodosa. Am J Pathol 1951;27:227-310.

2 Chumbley LC, Harrison EG, De Reinee RA. Allergic granulomatosis and angitiis (Churg Strauss syndrome). Mayo Clin Proc 1977;52:477-81.

3 Lanham JG, Elkon KB, Pusey CD, Hughes GR. Systemic vasculitis with asthma and eosinophilia: a clinical approach to the Churg Strauss syndrome. Medicine (Baltimore) 1984;63:65-81.

4 Oakley CM, Olsen EGJ. Eosinophilia and heart disease. Br Heart J 1977;39:233-7.

5 Logan-Sinclair R, Wong CM, Gibson DG. Clinical application of amplitude processing of echocardiographic images. Br Heart $J$ 1981;45:621-7.

6 Upton MT, Gibson DG. The study of left ventricular function from digitised echocardiograms. Prog Cardiovasc Dis 1978;20:359-84.

7 Bradley JA, Gibson DG. Assessment of the severity of mitral regurgitation from the dynamics of retrograde flow. Br Heart J 1988;60:134-40.

8 Roberts WC, Liegler DG, Carbone PP. Endomyocardial disease and eosinophilia. A clinical and pathological spectrum. Am J Med 1969;46:28-42.

9 Olsen EGJ, Spry CJF. Relationship between eosinophilia and endomyocardial disease. Prog Cardiovasc Dis 1985;27:241-54.

10 Chusid MJ, Dale DC, West BC, Wolff SM. The hypereosinophilic syndrome: analysis of fourteen cases with review of the literature. Medicine (Baltimore) 1975;54:1-27.

11 Roberts WC, Buja LM, Ferrans VJ. Loefflers fibroplastic parietal endocarditis, eosinophilic leukaemia and Davies' endomyocardial fibrosis: the same disease at different stages? Pathologia et Microbiologia 1970;35:90-5.

12 Chew CYC, Ziady GM, Raphael MJ, Nellen M, Oakley CM. Primary restrictive cardiomyopathy: nontropical endomyocardial fibrosis and hypereosinophilic heart disease. Br Heart J 1977;39:399-413.

13 Spry CJF, Take M, Tai P-C. Eosinophilic disorders affecting the myocardium and endocardium: a review. Heart and Vessels 1985;suppl I:240-2.

14 Rosenberg TF, Medsger TA, DeCicco FA, Fireman P. Allergic granulomatosis angitiis (Churg-Strauss syndrome). J Allergy Clin Immunol 1975;55:56-9.

15 Davison AG, Thompson PJ, Davies J, Corrin B, Turner-Warwick M. Churg-Strauss syndrome (allergic granulomatosis and angitiis). Thorax 1983;38: 793-5.

16 Shaw TRD, Logan-Sinclair RB, Surin C, et al. Relation between regional echo intensity and myocardial connective tissue in chronic left ventricular disease. Br Heart J 1984;51:46-53.

17 Vijayaraghavan G, Davies J, Sadanandan S, Spry CJF, Gibson DG, Goodwin JF. Echocardiographic features of tropical endomyocardial disease in South India. Br Heart J 1983;50:450-9.

18 Davies J, Gibson DG, Foale R, et al. Echocardiographic features of eosinophilic endomyocardial disease. $\mathrm{Br}$ Heart $J$ 1982;48:434-40.

19 Swanson KT, Greenbaum RA, Logan-Sinclair RB, Gibson DG, Yacoub MH. Quantitative echocardiographic tissue characterisation after cardiac transplantation [Abstract]. Br Heart J 1988;59:629. 